\title{
The Influence E-Learning Platforms of Undergraduate Education in Iraq
}

\author{
https://doi.org/10.3991/ijes.v9i4.26995 \\ Haider TH. Salim ALRikabi ${ }^{1(\bowtie)}$, Duha Khalid Abdul-Rahman Al-Malah², \\ Ban Hassan Majeed ${ }^{3}$, Ahmed Z. Abass $^{4}$ \\ ${ }^{1}$ Wasit University, Wasit, Iraq \\ ${ }^{2}$ Northern Technical University, Mosul, Iraq \\ ${ }^{3}$ University of Baghdad, Baghdad, Iraq \\ ${ }^{4}$ Novosibirsk Military Institute of National Guard Troops, Novosibirsk, Russia \\ hdhiyab@uowasit.edu.iq
}

\begin{abstract}
During COVID-19 Pandemic and lockdown procedure, the educational system relies on technology to continue learning. Technology has become not only an activity but also a fundamental tool. Moreover, technology becomes the core media that allows education to happen. In Iraq Blended Learning used to overcome the pandemic and counting education Therefore, the use of computers and digital applications became part of daily life and for long hours. Therefore, properly designed digital educational activities linked to social media have become a powerful educational tool aimed at finding ways of effective learning. The use of interactive activities contributed to the growth of self-learning motivation and the building of a healthy mind capable of finding a way out for the advancement of educational reality when crises occurred. It has become impossible to do without mobile devices, because of the attractive features they have and the multiple advantages they provide in teaching mathematical, medical, and engineering sciences in universities of our study relied on comparing the most important educational platforms with the best operation for managing virtual classes and the auxiliary tools they contain, including adding materials, assignments, tests, and electronic attendance records with archiving classes and migrating students to the advanced stages, as it relied on the electronic administration mechanism. All of these procedures take place through the availability of the Internet.
\end{abstract}

Keywords-COVID-19, E-learning, internet of things, platforms, google classroom

\section{$1 \quad$ Introduction}

E-learning is a way to share information with students from all over the world. According to [1]. E-learning can be defined as a method of learning and education that makes use of the Internet or other multimedia materials. It takes full advantage of current educational technologies to offer a new medium for connectivity and a rich learning atmosphere to achieve a new way of learning. The electronic platforms that 
possess electronic content management systems and the features of social networking sites by offering assignments, study materials, and professional development courses with the possibility of submitting assignments, writing notes, polling opinions, writing reports, and scheduling study materials for education through virtual classes [2-6]. They are intensive electronic courses targeting a large number of students, and they consist of videos to explain the course provided by teaching experts, reading materials, and tests with the presence of social networking forums between students and professors, which are learning, teaching and research resources available through a digital or non-digital means of communication that have a version under an open license that allows Others have free access to, use, adaptation and distribution of it without any conditions or restrictions as shown in Figure 1.

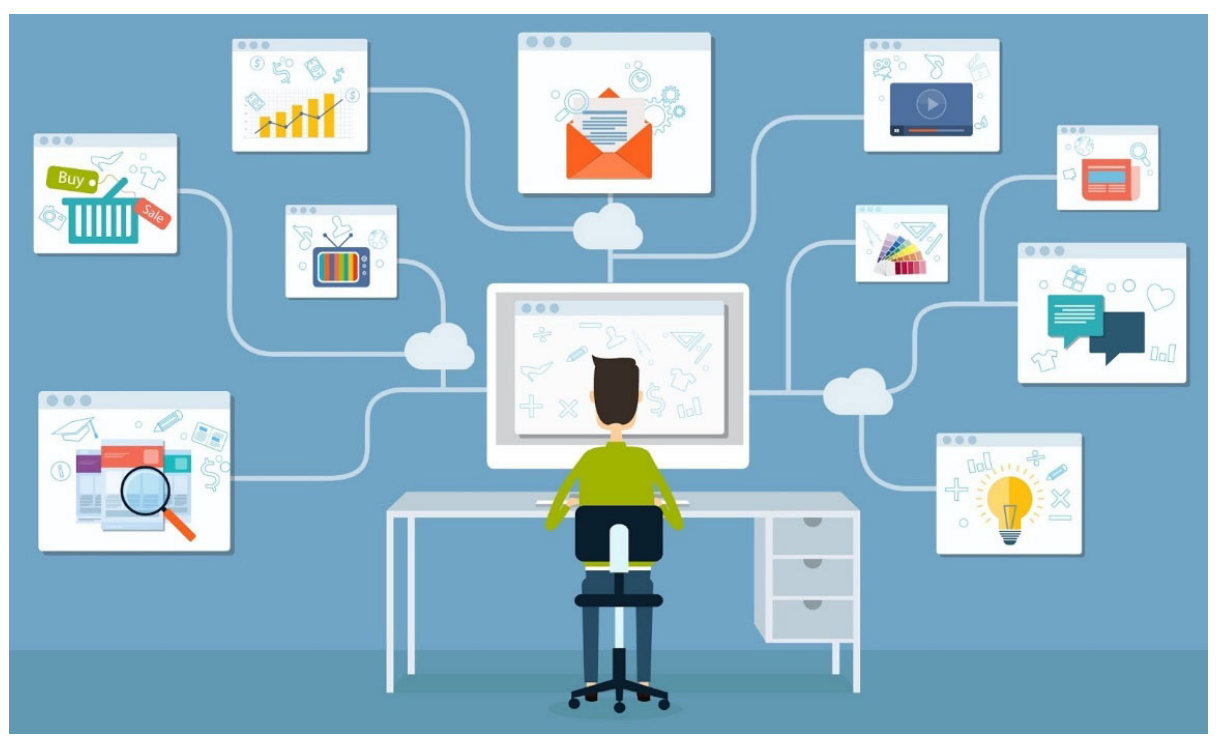

Fig. 1. Types of E-learning platform

E-learning is a smart technique and it is a very efficient method to provide and exchange information with the learner's team in different countries at the same time [7-9]. The electronic educational platforms are that interactive educational situation that employs web technology, combines the benefits of electronic content management systems and social networks, and enables teachers to publish lessons and goals, set assignments, implement educational activities, and communicate with teachers through multiple technologies, as it enables teachers from conducting electronic exams, distributing roles, dividing students into working groups are helping to exchange ideas and opinions between students and teachers which led to sharing scientific content and allowing parents to communicate with teachers and see the results of their children, which helps to achieve high-quality educational outcomes [10-14]. E-learning has also gained an increasing desire among students, and educational platforms have witnessed leaps in providing a complete interactive educational experience $[15,16,4,17,18]$. It is an integrated set of immersive online services which provide information, tools, and 
resources to trainers, learners, and others involved in education in order to support and improve the delivery and managerial staff of education. So, it offers the basic educational systems simply without complication with an interface through which users can interact with the educational content. So, Increasing the professor's knowledge, teaching skills, and competence, and increasing his insight into the educational problems that are accompanied by an increase in his success as a teacher. The study is related to the effectiveness of the Internet of Things (IoT) tools on educational platforms, which would facilitate the interaction between real education and virtual education [19-26]. The theoretical analysis with the questionnaire questions was explored through which the statistical results that showed an effect that cannot be ignored in the ecosystem of educational platforms in terms of classroom management and the addition of study materials in large quantities with the continuation of hyper-communication and the provision of physical and virtual objects, to make education a flexible and adaptable effect with a rapid dynamic to add the necessary educational tools upon the lecture.

Advantages of using electronic educational platforms [27-31].

1. Combining electronic content management systems with social networks.

2. It helps students exchange opinions and ideas, which helps creative thinking.

3. Teachers can create virtual classes for students.

4. Conducting group discussions, sending letters, and exchanging files between teachers and students.

5. Creating many groups on the electronic platform.

6. A digital library that contains learning resources for the scientific content.

7. It helps in creating electronic tests easily and provides feedback to students.

8. It helps teachers in monitoring the performance of their students in performing some skills and their progress.

9. Encourages students to participate in learning.

10. Solving the problem of private lessons by reaching non-traditional solutions to the problems of traditional teaching methods.

11. Allowing students to retrieve what they have studied at any time.

\section{Methodology}

\subsection{Study hypotheses}

Assumptions are considered that require validation and are formulated based on the hypothetical study mode. The first main hypothesis:

There is a significant correlation between E-learning platforms and the internet of the. The second main hypothesis:

There is a significant impact between E-learning platforms and the internet of things.

\subsection{Study methodology}

The present study relied on the descriptive and analytical methodology to achieve the objective of the study and answer the questions and choose the hypotheses through 
the two axes of theoretical and practical study to enable the compatibility between these parts of the study and analysis.

\subsection{Instrument}

After reviewing the relevant literature, a questionnaire with (24) statements was used in this study to collect primary data. It consists of two parts, the first of which is covered by demographic characteristics. The second section is dedicated to the independent and dependent variables.

\subsection{Approved sample}

The targets within the study are an educational community (lecturers and students) of the Iraq Universities. The method of taking this convenient sample to use in this study is very fast, easy, and cost-effective, which made it our preferred choice. Thus, one hundred and eight-five (185) electronic questionnaires were collected.

\section{Data analysis}

\subsection{Descriptive demographic data analysis}

As shown in Table 1 below. The descriptive analysis of the data indicates that the number of teachers that answer the questions is 24 , the percentage of them is $13 \%$ from the sample and the number of students is 161 , the percentage was $87 \%$. Younger students age between $15-25$ was 143 with $87.1 \%$ which is the highest percentage. Also, we can see the gender which is the highest percentage of male $76.8 \%$, the number of it was 142 , last, the using of platforms which is the highest percentage of $93.5 \%$ and 173 chooses the google classroom.

Table 1. Descriptive analysis - profile of respondents

\begin{tabular}{|l|l|c|c|}
\hline \multirow{3}{*}{ Types } & & NO. & The Percentage \\
\hline \multirow{4}{*}{ Age } & Teacher & 24 & 13 \\
\cline { 2 - 4 } & Student & 161 & 87 \\
\cline { 2 - 4 } & $15-25$ & 143 & 77.3 \\
\cline { 2 - 4 } & $25-35$ & 19 & 10.3 \\
\cline { 2 - 4 } & $35-45$ & 12 & 6.5 \\
\cline { 2 - 4 } & $45-55$ & 9 & 4.9 \\
\cline { 2 - 4 } & More than 55 & 2 & 1.1 \\
\hline \multirow{3}{*}{ Plateformes } & Male & 142 & 76.80 \\
\cline { 2 - 4 } & Female & 173 & 23.2 \\
\cline { 2 - 4 } & Google Classroom & 7 & 93.50 \\
\cline { 2 - 4 } & Moodle & 5 & 3.80 \\
\cline { 2 - 4 } & Edmodo & 2.7 \\
\hline
\end{tabular}




\subsection{Findings and discussions}

The results indicate that educational platforms such as (Google Class Room, Edmodo, and Model) are linked to the availability of Internet of Things supplies in order to achieve satisfaction and acceptance of the shift from traditional education to blended education by providing easy-to-use and clear-to-use tools, as well as smart handling of modern technologies with a sophisticated nature that is moving towards accepting the idea of blended learning. Where the study indicate that the effect of educational platforms with the effectiveness of the Internet to satisfy participants in a session to obtain the lecture with the possibility of student interaction when joining the lecture is fully linked to the Internet of things and included (smart panels, monitoring devices, remote control, virtual classes with triple deal dimension) increase students' knowledge capacity and encourage them to innovate and diversify by presenting them with interesting and appealing methods, which led to the following assumptions:

Main hypothesis H0: There is a significant effect of educational platforms on the Internet of things. Where the researchers divided the sample and the answers into two parts: There is a significant impact among educational platforms on the Internet of things. To sort the statistical analysis into two results:

The first is - the statistical analysis of students: as shown in Table 2, the highest marginal percentage is $34.2 \%$ with 55 repetitions, that is main the paragraph (I think our university has an internet connection available to everyone). It has a strong influence on the internet of things.

Table 2. The repetitions of the questionnaires and case processing

\begin{tabular}{|l|c|c|c|}
\hline \multicolumn{2}{|c|}{} & N & Marginal Percentage \\
\hline \multirow{4}{*}{ IoT } & 1.00 & 16 & $9.9 \%$ \\
\cline { 2 - 4 } & 2.00 & 38 & $23.6 \%$ \\
\cline { 2 - 4 } & 3.00 & 55 & $34.2 \%$ \\
\cline { 2 - 4 } & 4.00 & 41 & $25.5 \%$ \\
\cline { 2 - 4 } & 5.00 & 11 & $6.8 \%$ \\
\hline Total & 161 & \\
\hline
\end{tabular}

Statistical tests were performed on the SPSSspss system on the ordinal scale (PLU), for independence was examined in the study to demonstrate the relationship between the two variables as shown in Table 3, education platforms and the Internet of things at the level of significance, the model produce the value of $F$ computed with a value of (73.544) in sig. $=(\mathbf{0 . 0 0 0})$. Chi-square is (15.54) and the value of the deviance is (19.825), which indicates the presence of a significant effect.

Table 3. The model for student's answers

\begin{tabular}{|c|c|c|c|c|c|c|}
\hline \multicolumn{6}{|c|}{ Model Fitting Information } & \multirow[b]{2}{*}{ Pearson } \\
\hline Model & -2 Log Likelihood & Chi-Square & df & Sig. & Deviance & \\
\hline Intercept Only & 89.084 & & & & & \\
\hline Final & 73.544 & 15.540 & 15 & 0.000 & 19.825 & 19.339 \\
\hline \multicolumn{5}{|c|}{ Link function: Logit. } & & \\
\hline
\end{tabular}


As shown in Table 4: the estimates parameters in student model, the statements (I think educational platforms have reduced educational costs) and (Think educational platforms have standardized curricula and decisions for all universities), the values of the estimation tests are $(4.675,2.700)$, in value of $\operatorname{sig}=0.000$, the and the answer tends towards [(agree), (strongly agree)]. These values in the model reflect the quality of the statistical analysis in the student's model. So, rejecting the null hypothesis and accepting the alternative hypothesis.

Table 4. The parameter estimates for students

\begin{tabular}{|c|c|c|c|c|c|c|c|c|}
\hline & & & Std. & & & Sim & $\begin{array}{r}95 \% \text { C } \\
\text { In }\end{array}$ & $\begin{array}{l}\text { fidence } \\
\text { val }\end{array}$ \\
\hline & & Estmate & Error & Waid & an & Sig. & $\begin{array}{l}\text { Lower } \\
\text { Bound }\end{array}$ & $\begin{array}{l}\text { Upper } \\
\text { Bound }\end{array}$ \\
\hline Threshold & {$[\mathrm{IoT}=1.00]$} & 0.408 & 0.514 & 0.631 & 1 & 0.427 & -1.416 & 0.599 \\
\hline & {$[\mathrm{IoT}=2.00]$} & 1.179 & 0.505 & 5.453 & 1 & 0.020 & 0.189 & 2.168 \\
\hline & {$[\mathrm{IoT}=3.00]$} & 2.700 & 0.541 & 24.958 & 1 & 0.000 & 1.641 & 3.760 \\
\hline & {$[\mathrm{IoT}=4.00]$} & 4.675 & 0.622 & 56.478 & 1 & 0.000 & 3.456 & 5.894 \\
\hline Location & Plate & 0.545 & 0.138 & 15.573 & 1 & 0.000 & 0.274 & 0.815 \\
\hline
\end{tabular}

The second is - the statistical analysis of academic teachers: as shown in Table 5, the highest marginal percentage is $50 \%$ with 12 repetitions, that is main the statement (I think educational platforms increased my working hours and exposure). It has a strong influence on the internet of things.

Table 5. The repetitions of the questionnaires and case processing

\begin{tabular}{|l|c|c|c|}
\hline \multicolumn{2}{|c|}{} & N & Marginal Percentage \\
\hline \multirow{3}{*}{ IoT } & 1.00 & 6 & $25.0 \%$ \\
\cline { 2 - 4 } & 2.00 & 12 & $50.0 \%$ \\
\cline { 2 - 4 } & 3.00 & 5 & $20.8 \%$ \\
\cline { 2 - 4 } & 4.00 & 1 & $4.2 \%$ \\
\hline Valid & 24 & $100.0 \%$ \\
\hline
\end{tabular}

Statistical tests were performed on the SPSS system on the ordinal scale (PLU), for independence was examined on the study to demonstrate the relationship between the two variables as shown in Table 6, education platforms and the Internet of things at the level of significance, the model produce the value of $\mathrm{F}$ computed with a value of (22.844) in sig. $=(\mathbf{0 . 0 0 0})$. Chi-square is (1.141) and the value of the deviance is (10.665), which indicates the presence of a significant effect. 
Table 6. The model fitting information for academic teacher's answers

\begin{tabular}{|l|c|c|c|c|c|c|}
\hline \multicolumn{1}{|c|}{ Model } & $\begin{array}{c}-\mathbf{2} \text { Log } \\
\text { Likelihood }\end{array}$ & Chi-Square & Df & Sig. & Deviance & Pearson \\
\hline Intercept Only & 23.985 & & & & & \\
\hline Final & 22.844 & 1.141 & 5 & .000 & 10.665 & 9.380 \\
\hline \multicolumn{7}{|l}{ Link function: Logit. } \\
\hline
\end{tabular}

As shown in Table 7: the estimates parameters in student model, the statement (I think educational platforms reduce classroom availability), the value of the estimation test is (4.963), and the value of sig $=0.000$, and the answer tends towards (strongly agree). These values in the model reflect the quality of the statistical analysis in the student's model. So, rejecting the null hypothesis and accepting the alternative hypothesis.

Table 7. The parameter estimates for academic teachers

\begin{tabular}{|c|c|c|c|c|c|c|c|c|}
\hline & & \multirow{2}{*}{ Estimate } & \multirow{2}{*}{$\begin{array}{l}\text { Std. } \\
\text { Error }\end{array}$} & \multirow{2}{*}{ Wald } & \multirow{2}{*}{ df } & \multirow{2}{*}{ Sig. } & \multicolumn{2}{|c|}{$\begin{array}{l}\text { 95\% Confidence } \\
\text { Interval }\end{array}$} \\
\hline & & & & & & & $\begin{array}{l}\text { Lower } \\
\text { Bound }\end{array}$ & $\begin{array}{l}\text { Upper } \\
\text { Bound }\end{array}$ \\
\hline \multirow[t]{3}{*}{ Threshold } & {$[\mathrm{IoT}=1.00]$} & 0.554 & 1.667 & 0.111 & 1 & 0.739 & 2.713 & 3.822 \\
\hline & {$[\mathrm{IoT}=2.00]$} & 2.839 & 1.780 & 2.545 & 1 & 0.111 & 0.649 & 6.327 \\
\hline & {$[\mathrm{IoT}=3.00]$} & 4.963 & 2.041 & 5.910 & 1 & 0.015 & 0.962 & 8.963 \\
\hline Location & plate & 0.512 & 0.485 & 1.116 & 1 & 0.291 & 0.438 & 1.463 \\
\hline
\end{tabular}

\section{Conclusions}

The study emerged with several conclusions, as follows:

1. The category used for educational platforms is the category of youth students, whose ages range between 15 and 25 .

2. The male category's preference for females to enter educational platforms, which indicates that females prefer to use books, textbooks, and traditional reading, while males prefer the quick, shortened method.

3. Ease of use of educational platforms with the availability of the Internet and the Internet of things, which contributed to the development and progress of sober digital education.

4. For the two teachers, difficulties arose when using the educational platforms, which is the increase in the number of hours of preparing lectures and the necessity of self-reliance by creating interactive videos and creating virtual classes.

5. Virtual classrooms reduced material expenses in terms of establishing classrooms that accommodate large numbers of students.

6. The necessity of granting the codes to students to register and enter through an official code that facilitates access to the student's scientific and personal data and 
provides an electronic database that can be managed remotely with the availability of a group of servers and cloud servers, while ensuring the security of information.

7. The reluctance of some professors to use the educational platforms in the exams because of a case of collective cheating and the failure to bring out the hardworking student from the lazy student.

8. The necessity to provide internet tools, including the smart board in every class or laboratory, so that the science lesson can be followed up electronically.

9. Gaining creative skills through open discussions between the professor and the student to build a scientific team that contributes to supporting the development of digital education.

10. Involve students in lectures and qualifying courses to follow them and not waste their free time with trivial matters that limit the expansion of their perceptions to provide them with the necessary experience to provide them with suitable work after graduating from the university.

\section{$5 \quad$ References}

[1] A. J. Kristanto, "The development of instructional materials E-learning based on blended learning," International Education Studies, vol. 10, no. 7, pp. 10-17, 2017. https://doi. org/10.5539/ies.v10n7p10

[2] A. Raes, L. Detienne, and I. Windey, "A systematic literature review on synchronous hybrid learning: gaps identified," Learning Environments Research, vol. 23, no. 3, pp. 269-290, 2020. https://doi.org/10.1007/s10984-019-09303-Z

[3] D. Halvoník, and J. Kapusta, "Framework for E-learning materials optimization," International Journal of Emerging Technologies in Learning (iJET), vol. 15, no. 11, pp. 67-77, 2020. https://doi.org/10.3991/ijet.v15i11.12721

[4] D. Abdul-Rahman Al-Malah, and H. ALRikabi, "Enhancement of educational services by using the internet of things applications for talent and intelligent schools," Periodicals of Engineering and Natural Sciences (PEN), vol. 8, no. 4, pp. 2358-2366, 2020.

[5] A. H. M. Alaidi, O. H. Yahya, and H. T. S. AlRikabi, "Using modern education technique in Wasit university," International Journal of Interactive Mobile Technologies, Article vol. 14, no. 6, pp. 82-94, 2020. https://doi.org/10.3991/ijim.v14i06.11539

[6] N. A. Jasim, H. T. S. AlRikabi, and M. S. Farhan, "Internet of Things (IoT) application in the assessment of learning process," in IOP Conference Series: Materials Science and Engineering, 2021, vol. 1184, no. 1, p. 012002: IOP Publishing. https://doi.org/10.1088/ 1757-899X/1184/1/012002

[7] M. N. Giannakos, P. Mikalef, and I. Pappas, "Systematic literature review of E-learning capabilities to enhance organizational learning," Information Systems Frontiers, pp. 1-17, 2021. https://doi.org/10.1007/s10796-020-10097-2

[8] A. Klašnja-Milićević, B. Vesin, M. Ivanović, Z. Budimac, and L. C. Jain, E-learning systems: Intelligent techniques for personalization. Springer, 2016. https://doi. org/10.1007/978-3-319-41163-7

[9] H. Alrikabi, "Enhanced Data Security of Communication System using Combined Encryption and Steganography," International Journal of Interactive Mobile Technologies, vol. 15, no. 16, pp. 144-157, 2021. https://doi.org/10.3991/ijim.v15i16.24557

[10] S. Ennouamani, and Z. Mahani, "A context-aware mobile learning system for adapting learning content and format of presentation: design, validation and evaluation," Education and Information Technologies, pp. 1-37, 2020. https://doi.org/10.1007/s10639-020-10149-9 
[11] D. Al-Malah, Haider, T. H. Salim ALRikabi, "The Interactive Role Using the Mozabook Digital Education Application and its Effect on Enhancing the Performance of E-learning," International Journal of Emerging Technologies in Learning (iJET), vol. 15, no. 20, pp. 21-41, 2020. https://doi.org/10.3991/ijet.v15i20.17101

[12] L. F. Jawad, B. H. Majeed, and H. T. ALRikabi, "The Impact of Teaching by Using STEM Approach in The Development of Creative Thinking and Mathematical Achievement Among the Students of The Fourth Scientific Class," International Journal of Interactive Mobile Technologies, vol. 15, no. 13, pp. 172-188, 2021. https://doi.org/10.3991/ijim.v15i13.24185

[13] A. Al-zubidi, R. K. Hasoun, and H. Alrikabi, "Mobile Application to Detect Covid-19 pandemic by using Classification Techniques: Proposed System," International Journal of Interactive Mobile Technologies, vol. 15, no. 16, pp. 34-51, 2021. https://doi.org/10.3991/ ijim.v15i16.24195

[14] B. H. Majeed , L. F. Jawad, and H. Salim, "The Impact of CATs on Mathematical Thinking and Logical Thinking Among Fourth-Class Scientific Students," International Journal of Emerging Technologies in Learning (iJET), vol. 16, no. 10, pp. 194-211, 2021. https://doi. org/10.3991/ijet.v16i10.22515

[15] R. Ellis, and P. Goodyear, Students' experiences of E-learning in higher education: the ecology of sustainable innovation. Routledge, 2013. https://doi.org/10.4324/9780203872970

[16] D. Al-Malah, H. Salim, and H. Mutar, "Cloud Computing and its Impact on Online Education," IOP Conference Series: Materials Science and Engineering, vol. 1094, p. 012024, 2021. https://doi.org/10.1088/1757-899X/1094/1/012024

[17] A. Khairy, and H. TH. Salim, "The Detection of Counterfeit Banknotes Using Ensemble Learning Techniques of AdaBoost and Voting," International Journal of Intelligent Engineering and Systems, vol. 14, no. 1, pp. 326-339, 2021. https://doi.org/10.22266/ijies2021.0228.31

[18] O. H. Yahya, H. T. S. AlRikabi, R. M. Al_Airaji, and M. Faezipour, "Using internet of things application for disposing of solid waste," International Journal of Interactive Mobile Technologies, Article vol. 14, no. 3, pp. 4-18, 2020. https://doi.org/10.3991/ijim.v14i13.13859

[19] M. B. Abbasy, "Predictable influence of IoT (Internet of Things) in the higher education," International Journal of Information and Education Technology, vol. 7, no. 12, pp. 914-920, 2017. https://doi.org/10.18178/ijiet.2017.7.12.995

[20] M. Al-Emran, S. I. Malik, and M. N. Al-Kabi, "A Survey of Internet of Things (IoT) in Education: Opportunities and Challenges," in Toward Social Internet of Things (SIoT): Enabling Technologies, Architectures and Applications: Springer, 2020, pp. 197-209. https://doi.org/10.1007/978-3-030-24513-9 12

[21] Y. S. Mezaall, L. N. Yousif, and Z. J. Abdulkareem, "Review about effects of IOT and Nano-technology techniques in the development of IONT in wireless systems," International Journal of Engineering \& Technology, vol. 7, no. 4, pp. 3602-3606, 2018.

[22] B. K. Mohammed, M. B. Mortatha, A. S. Abdalrada, and H. ALRikabi, "A comprehensive system for detection of flammable and toxic gases using IoT," Periodicals of Engineering and Natural Sciences (PEN), vol. 9, no. 2, pp. 702-711, 2021.

[23] B. Mohammed, R. Chisab, and H. Alrikabi, "Efficient RTS and CTS Mechanism Which Save Time and System Resources," International Journal of Interactive Mobile Technologies, vol. 14, no. 4, pp. 204-211, 2020. https://doi.org/10.3991/ijim.v14i04.13243

[24] A. S. Hussein, R. S. Khairy, S. M. M. Najeeb, and H. ALRikabi, "Credit Card Fraud Detection Using Fuzzy Rough Nearest Neighbor and Sequential Minimal Optimization with Logistic Regression,” International Journal of Interactive Mobile Technologies, vol. 15, no. 5, 2021. https://doi.org/10.3991/ijim.v15i05.17173

[25] N. A. Hussien, A. A. Daleh Al-Magsoosi, H. T. AlRikabi, and F. Abed, "Monitoring the Consumption of Electrical Energy Based on the Internet of Things Applications," International Journal of Interactive Mobile Technologies, vol. 15, no. 7, 2021. https://doi. org/10.3991/ijim.v15i07.20183 
[26] H. Salim, and N. Jassim "Design and Implementation of Smart City Applications Based on the Internet of Things," iJIM, vol. 15, no. 3, 2021. https://doi.org/10.3991/ijim.v15i13.22331

[27] E. G. Sabirova, "Features and advantages of using websites in teaching mathematics (Interactive educational platform UCHI. ru)," Eurasia Journal of Mathematics, Science and Technology Education, vol. 15, no. 5, p. em1729, 2019. https://doi.org/10.29333/ ejmste/108367

[28] N. S. Alseelawi, E. K. Adnan, H. T. Hazim, H. Alrikabi, and K. Nasser, "Design and Implementation of an E-learning Platform Using N-Tier Architecture," International Journal of Interactive Mobile Technologies, vol. 14, no. 6, pp. 171-185, 2020. https://doi.org/10.3991/ ijim.v14i06.14005

[29] L. Chikileva, "Implementation of electronic platforms in language learning: benefits for teachers and students," Cross-Cultural Studies: Education and Science, no. 3, pp. 381-386, 2018.

[30] K. Khaleel, "Cloud computing investigation for cloud computer networks using cloudanalyst," Journal of Theoretical and Applied Information Technology, vol. 96, no. 20, 2018.

[31] B. Majeed, H. Salim Alrikabi, "Tactical Thinking and its Relationship with Solving Mathematical Problems Among Mathematics Department Students," International Journal of Emerging Technologies in Learning (iJET), vol. 16, no. 9, pp. 247-262, 2021. https://doi. org/10.3991/ijet.v16i09.22203

\section{Authors}

Haider Th. Salim ALRikabi: He is presently Asst. Prof and one of the faculty College of Engineering, Electrical Engineering Department, Wasit University in Al Kut, Wasit, Iraq. He received his B.Sc. degree in Electrical Engineering in 2006 from the Al Mustansiriya University in Baghdad, Iraq. His M.Sc. degree in Electrical Engineering focusing on Communications Systems from California state university/Fullerton, USA in 2014. His current research interests include Communications systems with the mobile generation, Control systems, intelligent technologies, smart cities, and the Internet of Things (IoT), Renewable Energy. Al Kut city—Hay ALRabee, Wasit, Iraq. E-mail: hdhiyab@uowasit.edu.iq. The number of articles in national databases-10, and the number of articles in international database- 40 .

Duha Khalid Abdul-Rahman Al-Malah: She is a Lecturer, she is the Reporter Department of Tourism and Hotel Management, Responsible of the Central Library Division, Instructor for Calculator Applications Course in Nenawa Institute, Northern Technical University, Mosul, Iraq. Higher diploma in computers, E-learning and education. E-mail: Duhakm@ntu.edu.iq. The number of articles in national databases_4, The number of articles in international databases-2.

Ban Hassan Majeed: She is presently the lecturer and one of the faculty of the computer department, College of Education for Pure Sciences/Ibn Al- Haitham, University of Baghdad, Iraq. Her current research interests include methods of teaching mathematics, thinking, thinking skills, multiple Intelligences, educational technology, Technological innovations. Email: ban.h.m@ihcoedu.uobaghdad.edu.iq

Ahmed Z. Abass, Novosibirsk Military Institute of National Guard Troops, Novosibirsk, Russia.

Article submitted 2021-09-18. Resubmitted 2021-10-14. Final acceptance 2021-10-14. Final version published as submitted by the authors. 